Short paper

\title{
Nicotine-induced brain metabolism associated with anger provocation
}

\author{
Jean-G Gehricke*1, Steven G Potkin ${ }^{1}$, Frances M Leslie ${ }^{2}$, Sandra E Loughlin², \\ Carol K Whalen ${ }^{3}$, Larry D Jamner ${ }^{3}$, James Mbogori ${ }^{1}$ and James H Fallon ${ }^{4}$
}

\begin{abstract}
Address: ${ }^{1}$ Department of Psychiatry and Human Behavior, University of California, Irvine, 19722 MacArthur Blvd., Irvine, California 92612, USA, ${ }^{2}$ Department of Pharmacology, University of California, Irvine, CA, USA, ${ }^{3}$ Department of Psychology and Social Behavior, University of California, Irvine, CA, USA and ${ }^{4}$ Department of Anatomy and Neurobiology, University of California, Irvine, CA, USA

Email: Jean-G Gehricke* - jgehrick@uci.edu; Steven G Potkin - sgpotkin@uci.edu; Frances M Leslie - fmleslie@uci.edu; Sandra E Loughlin - loughlin@uci.edu; Carol K Whalen - ckwhalen@uci.edu; Larry D Jamner - ljamner@uci.edu; James Mbogori - jmbogori@uci.edu; James H Fallon - jfallon@es.nacs.uci.edu

* Corresponding author
\end{abstract}

Published: 24 April 2009

Behavioral and Brain Functions 2009, 5:19 doi:10.1186/1744-9081-5-19
Received: 12 November 2008

Accepted: 24 April 2009

This article is available from: http://www.behavioralandbrainfunctions.com/content/5/I/19

(C) 2009 Gehricke et al; licensee BioMed Central Ltd.

This is an Open Access article distributed under the terms of the Creative Commons Attribution License (http://creativecommons.org/licenses/by/2.0), which permits unrestricted use, distribution, and reproduction in any medium, provided the original work is properly cited.

\begin{abstract}
Cortico-limbic brain activity associated with anger may be susceptible to nicotine and, thus, may contribute to smoking initiation and nicotine addiction. The purpose of the study was to identify the brain regions that are most reactive to nicotine and show the greatest association with anger task performance. Twenty adult nonsmokers ( 9 women, II men) participated in two laboratory sessions to assess brain metabolism with fluoro deoxy-glucose Positron Emission Topography (FDG-PET) in response to nicotine and placebo patches during an anger provocation task. Outcome variables for the anger provocation task were reaction time, intensity and length of retaliation. Reaction time was associated with nicotine-induced changes in the left thalamus. Length of retaliation was associated with a functionally linked set of cortical and subcortical structures such as right frontal lobe, right anterior cingulate (BA 24), right uncus, left parietal lobe, left BA II, left cingulate, left BA 25, left amygdala, left BA 30 , left BA 38 and BA 9. These findings reveal the underlying brain circuitry targeted by nicotine during anger provocation.
\end{abstract}

\section{Findings}

Cigarette smoking is a major public health problem, and angry dispositions have been identified as an important risk factor for smoking initiation and subsequent nicotine dependence [1-4]. In particular, behavioral studies revealed a smoking-anger linkage [5-8], but little is known about the underlying brain circuitry subserving such linkage.

Dysfunctional cortico-limbic brain activity associated with anger may be normalized by nicotine [4]. Functional imaging studies on regional brain activity in response to nicotine and smoking have documented the involvement of cortico-limbic structures such as the prefrontal cortex (including the dorsolateral prefrontal cortex, inferior frontal, medial frontal, and orbitofrontal gyri) [9-15], cingulate [12-16], thalamus $[11,13,15,17-19]$, and amygdala $[12,13,15,19]$. Similarly, anger has been associated with activation of the medial prefrontal cortex, orbitofrontal cortex, and anterior cingulate cortex [20-22]. However, little is known about which brain areas are most responsive to the effects of nicotine during anger provocation. The 
elevated risk of dependence and the greater difficulty quitting may result, in part, from nicotine-associated normalization of activity of cortico-limbic circuitry [4].

The cortico-limbic circuitry is part of the "prefrontal system", which was first described by Rosvold and Schwatzbart [23] (see also review by Divac [24]) and may be particularly sensitive to nicotine modulation. The objective of the present study was to identify the brain regions within the prefrontal system that are most reactive to the effects of nicotine and show the greatest association with anger task performance in nonsmokers. Nonsmokers were studied to determine the effects of a fixed low-dose of nicotine via patch without the confounding effects of smoking and nicotine withdrawal. It was hypothesized that nicotine-induced anger task performance is associated with nicotine-induced changes in the medial prefrontal cortex, orbitofrontal cortex, and anterior cingulate cortex.

Twenty adult nonsmokers ( 9 women, 11 men), with a mean age of $24(S D=6)$, were recruited from the community via ads and flyers. All participants were physically and mentally healthy based on medical history obtained by a physician (JM). Similar to previous research [25], nonsmokers were defined by self-reported smoking abstinence of at least 2 years prior to participation in the study and not having smoked more than 100 cigarettes in their lifetime. All participants provided written informed consent approved by the Institutional Review Board of the University of California, Irvine.

Each participant completed two laboratory sessions in randomized order: one with a $3.5 \mathrm{mg}$ low-dose transdermal nicotine patch (Nicoderm; GlaxoSmithKline) and the other with a look-alike placebo patch. A $3.5 \mathrm{mg}$ nicotine patch (ie, $7 \mathrm{mg}$ patch cut in half) was used to minimize potential side-effects in nonsmokers. The two laboratory sessions examined the acute effects of nicotine compared to placebo on brain metabolism using fluoro deoxy-glucose Positron Emission Topography (FDG-PET) during an anger provocation task [26]. The anger provocation task was a computerized Competitive Reaction Time task (CRT) designed to induce and measure retaliatory tendencies. Each participant competed with an ostensible "opponent" (of the same sex) to respond to a visual stimulus (ie, red square) as quickly as possible. We enhanced the saliency of the "opponent" by incorporating a video clip of this person. The participant was asked to set the level of white noise (0-105 dB) she/he wanted the opponent to receive if the opponent lost. After the participant set the noise level, a yellow square appeared as a "get ready" cue, followed by the red square. The objective was to press a mouse button as fast as possible. A scale on the left side of the monitor indicated the noise level the opponent set for the participant to receive. Provocation was manipulated by increasing the noise level presumably set by the opponent across time. There were 25 trials, with white noise presented during approximately $50 \%$ of the trials. The noise blasts were delivered through headphones for a variable length of time (set by the participant from trial to trial). Output variables were average reaction time, intensity, and length of retaliation.

Regions of interest were identified and verified with the Talairach and Tournoux atlas [27] and included areas that are associated primarily with the prefrontal system [24]. These areas cut across prefrontal, temporal and limbic regions (see Table 1).

Each laboratory session lasted approximately 4.5 hours. First, the patch was worn for 3 hours. Then an intravenous injection of $5 \mathrm{mCi}$ of FDG was given during the 30-minute CRT. Subsequently, the subject lay in the scanner for 1 hour (see Fallon et al. [25] for more details). Patch administration was verified by serum cotinine levels (see Table 2).

For the PET data, normalized metabolic averages per anatomical region per subject were used. The metabolic averages were rescaled in order to reduce inter-individual variability in brain metabolism, and the resulting absolute metabolic averages per anatomical region per subject were used. Rescaling was achieved by taking the mean of all the brain regions within a subject (ie, global mean) and scaling it to the canonical normal global cerebral blood flow $(50 \mathrm{ml} / \mathrm{min} / \mathrm{dl})$. This is a common technique used when analyzing PET data and provides some protection against false positives from global cerebral blood

\section{Table I: Regions of Interest}

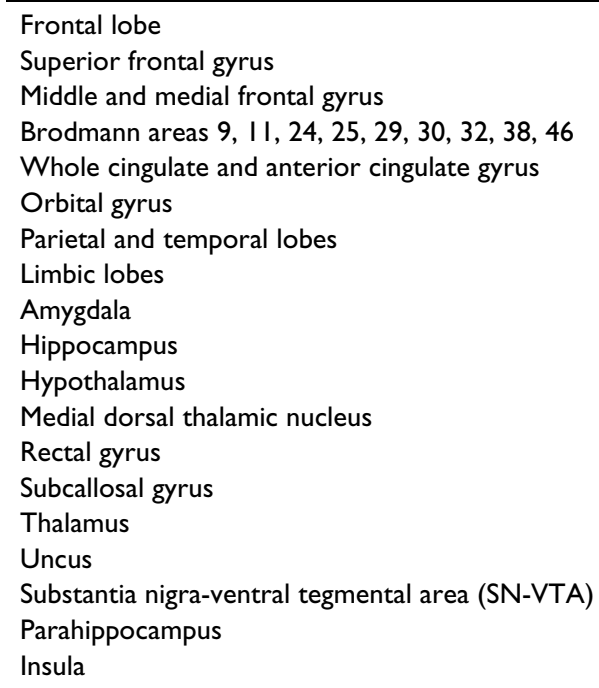

Regions of interest were examined independently for left and right hemisphere activity 
Table 2: Changes between nicotine versus placebo conditions in response to anger provocation

\begin{tabular}{|c|c|c|c|c|}
\hline Variables & $\begin{array}{c}\text { Placebo } \\
\text { Mean (SD) }\end{array}$ & $\begin{array}{l}\text { Nicotine } \\
\text { Mean (SD) }\end{array}$ & $t(19)$ & $P \leq$ \\
\hline \multicolumn{5}{|l|}{ Cotinine Levels $\mathrm{s}^{\mathrm{a}}$} \\
\hline Before patch & $0.00(0.00)$ & $0.00(0.00)$ & $\mathrm{N} / \mathrm{A}$ & $N / A$ \\
\hline After patch & $0.00(0.00)$ & $18.79(24.20)$ & 4.02 & 0.001 \\
\hline \multicolumn{5}{|l|}{ Region of Interest ${ }^{b}$} \\
\hline Left BA II & $410.78(66.19)$ & $386.20(68.04)$ & 2.26 & 0.036 \\
\hline Right BA II & $406.76(68.57)$ & $381.19(73.84)$ & 2.60 & 0.018 \\
\hline Right BA 29 & $482.28(63.03)$ & $503.19(65.90)$ & 2.31 & 0.032 \\
\hline Right Rectal Gyrus & $424.02(65.31)$ & $388.98(92.56)$ & 2.46 & 0.024 \\
\hline \multicolumn{5}{|l|}{ CRT } \\
\hline Reaction time ${ }^{c}$ & $284.57(70.78)$ & $281.52(77.02)$ & 0.17 & NS \\
\hline Intensity of Retaliation ${ }^{\mathrm{b}}$ & $5.53(2.03)$ & $5.59(2.16)$ & 0.13 & NS \\
\hline Length of Retaliationc & $290.50(213.91)$ & $319.92(241.93)$ & 0.82 & NS \\
\hline
\end{tabular}

\footnotetext{
$\mathrm{a}$ in $\mathrm{ng} / \mathrm{ml}$

$\mathrm{b}$ in arbitrary units

c in ms
}

flow changes under a treatment condition $[25,28]$. Preliminary analyses using $t$-tests revealed that BA 11 and right rectal gyrus metabolism was significantly reduced under nicotine compared to placebo patches, whereas BA 29 showed the opposite pattern (see Table 2). No other significant differences were found [see Additional file 1].

For the anger provocation task, the CRT outcome measures of reaction time, intensity and length of retaliation were averaged across the duration of the task. No significant mean differences were found in anger task performance between nicotine and placebo conditions, perhaps due to the low-dose nicotine patch (see Table 2). Group means, however, do not reflect individual differences in brain metabolism in response to nicotine. Therefore, stepwise linear regression models were used to examine delta scores for each outcome variable in order to contrast nicotine with placebo conditions (nicotine - placebo patch). Stepwise linear regression models (SPSS 13.0) examined which areas of the prefrontal system under nicotine compared to placebo predicted CRT outcome variables in response to nicotine versus placebo. Dependent variables were the total scores on CRT outcome variables. Predictor variables were the regions of interest. The inclusion criterion used in each regression model was a probability value of 0.05 . The exclusion criterion was a probability value of 0.06 . To adjust for the number of brain regions, alpha was Bonferroni-corrected at 0.0008 .

Table 3: Stepwise linear regression for reaction time and length of retaliation

\begin{tabular}{|c|c|c|c|c|c|c|}
\hline Dependent Variable & Predictors $^{\mathrm{a}}$ & Beta & $t$ & $P<$ & $R^{2}$ & Collinearity \\
\hline Reaction Time & Left Thalamus & -0.750 & 4.538 & 0.0001 & 0.563 & 1.000 \\
\hline \multicolumn{7}{|l|}{ Length of Retaliation } \\
\hline & Left Cingulate Gyrus & -0.599 & 39.660 & 0.0001 & 1.000 & 1.218 \\
\hline & Right Uncus & 1.068 & 107.318 & 0.0001 & & 1.649 \\
\hline & Left Amygdala & -0.349 & 43.520 & 0.0001 & & 1.906 \\
\hline & Left BA 9 & 0.679 & 56.707 & 0.0001 & & 2.241 \\
\hline & Right Frontal Lobe & -0.635 & 45.924 & 0.0001 & & 2.950 \\
\hline & Right BA 24 & 0.245 & 19.426 & 0.0001 & & 3.281 \\
\hline & Left BA 30 & -0.319 & 27.823 & 0.0001 & & 3.479 \\
\hline & Left Parietal Lobe & 0.471 & 34.911 & 0.0001 & & 4.269 \\
\hline & Left BA 25 & 0.330 & 19.769 & 0.0001 & & 5.069 \\
\hline & Right BA 9 & 0.238 & 16.405 & 0.0001 & & 5.805 \\
\hline & Left BA II & 0.190 & 10.866 & 0.0001 & & 9.191 \\
\hline & Left BA 38 & -0.099 & 8.167 & 0.0001 & & 10.802 \\
\hline
\end{tabular}

a The order of the predictors reflects the order of the stepwise linear regression

b Condition Index (i.e., values above 15 may indicate possible collinearity problems) 

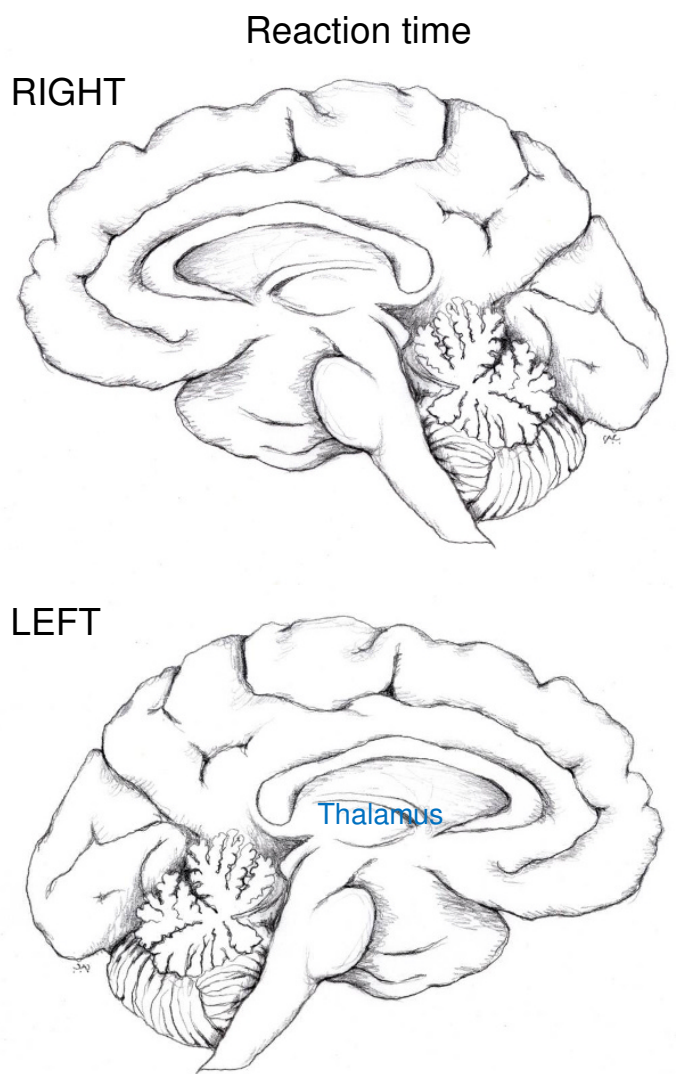
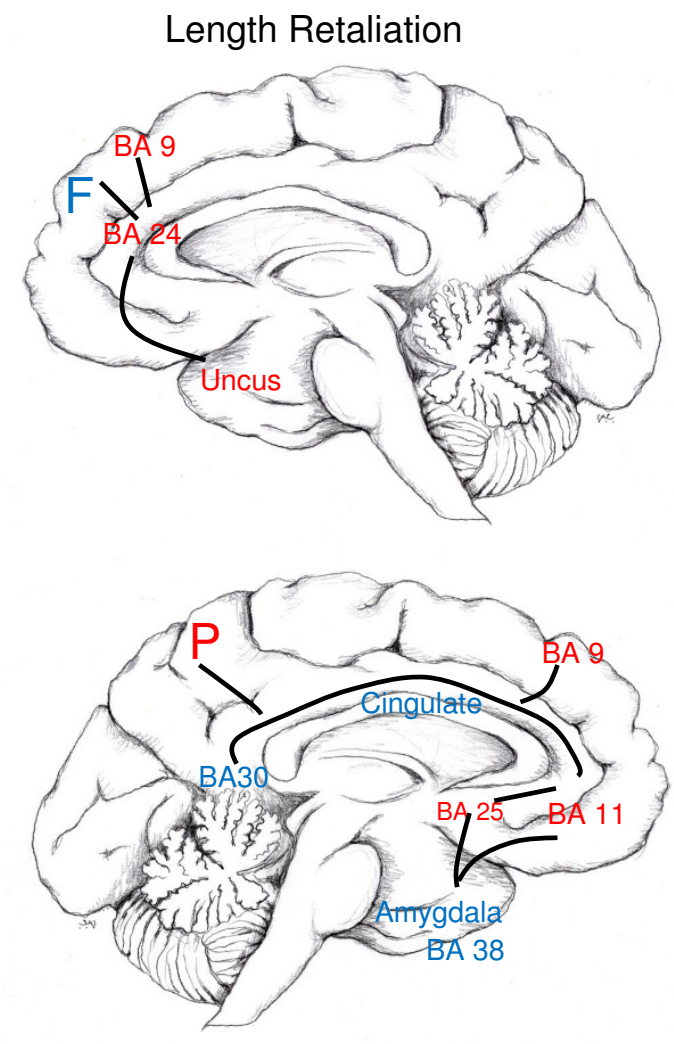

\section{Figure I}

Mid-sagittal drawing of cortical-limbic brain circuitry associated with anger provocation. Blue areas indicate decreased nicotine-induced brain metabolism associated with increased nicotine-induced task performance. Red areas indicate increased nicotine-induced brain metabolism associated with increased nicotine-induced task performance. Lines represent implied circuitry based on well-documented anatomical connectivity. $F=$ frontal lobe; $P=$ parietal lobe

The results from the regression models revealed that participants who showed nicotine-induced changes in anger task performance also showed changes in brain metabolism. More specifically, nicotine-induced improvements in reaction time were associated with decreased brain metabolism in response to nicotine in the left thalamus. This area of the brain explained $56 \%$ of variance for reaction time $\left(\mathrm{R}=0.75, \mathrm{R}^{2}=0.56\right.$, $\mathrm{F}$ change $(1,16)=20.59, \mathrm{p}$ $<0.0001)$.

Nicotine-induced reductions in length of retaliation were associated with increased brain metabolism in response to nicotine in the left cingulate, left amygdala, right frontal lobe, left BA 30, and left BA 38. In particular, the amygdala has been shown to modulate prefrontal regional activity [29]. However, our subjects included both women and men so that some underlying amygdaloid contribution may have been diluted by mixed lateralization components in women and men [30,31]. Positive associations were found between nicotine-induced reductions in length of retaliation and nicotine-induced reduction in brain metabolism in the orbital-frontal areas (ie, right uncus, left BA 9, right anterior cingulate (BA 24), left BA 25 , right $B A 9$, and left $B A 11$ ) and left parietal lobe. These predictors explained $100 \%$ of the variability in length of retaliation $\left(R=1.00, R^{2}=1.00\right.$, F change $(1,5)=66.69, p$ $<0.0001)$. No significant associations were found for intensity of retaliation. See Table 3 for more details.

The involvement of generalized cortical and subcortical areas may imply that nicotine-induced changes in anger task performance correlate with nicotine-induced changes in higher cortical and subcortical functioning responsible for orienting, planning, and processing of emotional stimuli. Our findings identify a circuitry (see Figure 1), that is primarily involved in the processing of emotional stimuli [29,32-41] and complex adaptive, motivated behaviors, including the regulation of emotion $[20,22,42-46]$.

The present findings on nicotine-induced brain metabolism in nonsmokers emphasize the role of negative affect, particularly anger, in susceptibility to nicotine. Moreover, 
the findings suggest that nicotine may critically regulate brain areas that are involved in the inhibition of negative emotions such as anger [43]. Deficits in anger management may be a risk factor for smoking initiation and nicotine addiction, which may highlight the importance of improving affect regulation as a potential smoking prevention and cessation strategy [4]. Novel neurotherapeutic and behavioral treatments (e.g., anger management training) that affect the cortical and limbic brain areas may aid smoking cessation efforts in anger provoking situations that increase withdrawal and tobacco cravings.

\section{Competing interests}

The authors declare that they have no competing interests.

\section{Authors' contributions}

JG conceptualized and coordinated the study, conducted the statistical analysis, and drafted the manuscript. SP directed the PET scanning and data processing. FL and SL initiated the research study, contributed to the research design, and reviewed drafts. CW and LJ aided in the conceptualization of the study, the interpretation of the data, and reviewed drafts. JM aided in the study coordination, obtained medical histories from participants, and reviewed drafts. JF identified and interpreted the ROIs with regards to task performance and aided in drafting Figure 1.

\section{Additional material}

\section{Additional file 1}

Metabolic averages in response to nicotine versus placebo associated with anger provocation. The data provide means and standard deviations for each region of interest in response to nicotine and placebo. Click here for file

[http://www.biomedcentral.com/content/supplementary/17449081-5-19-S1.doc]

\section{Acknowledgements}

This study was supported by the National Institute on Drug Abuse (TTURC; P50 DA I3332). We greatly appreciate the contributions of David Keator, Derek Taylor, Dennis Dierck, Rod Jiminez, Jessica Linford, and Allison Wright.

\section{References}

I. Gilbert DG, Gilbert BO: Personality, psychopathology, and nicotine response as mediators of the genetics of smoking. Behav Genet 1995, 25:133-147.

2. Lipkus IM, Barefoot JC, Feaganes J, Williams RB, Siegler IC: A short MMPI scale to identify people likely to begin smoking. J Pers Assess 1994, 62:213-222.

3. Whalen CK, Jamner LD, Henker B, Delfino RJ: Smoking and moods in adolescents with depressive and aggressive dispositions: evidence from surveys and electronic diaries. Health Psychol 200I, 20:99-III.

4. Gehricke J-G, Loughlin SE, Whalen CK, Potkin SG, Fallon JH, Jamner LD, Belluzzi JD, Leslie FM: Smoking to self-medicate attentional and emotional dysfunctions. Nicotine Tob Res 2007, 9 Suppl 4:S523-S536.

5. Cherek DR, Bennett RH, Grabowski J: Human aggressive responding during acute tobacco abstinence: effects of nicotine and placebo gum. Psychopharmacology (Berl) 1991, 104:317-322.

6. Jamner LD, Shapiro D, Jarvik ME: Nicotine reduces the frequency of anger reports in smokers and nonsmokers with high but not low hostility: an ambulatory study. Exp Clin Psychopharmacol 1999, 7:454-463.

7. Al'Absi M, Carr S, Bongard S: Anger and psychobiological changes during smoking abstinence and in response to acute stress: prediction of smoking relapse. Int J Psychophysiol 2007, 66:109-115.

8. Patterson F, Kerrin K, Wileyto EP, Lerman C: Increase in anger symptoms after smoking cessation predicts relapse. Drug Alcohol Depend 2008, 95: I73-I76.

9. Musso F, Bettermann F, Vucurevic G, Stoeter P, Konrad A, Winterer $\mathrm{G}$ : Smoking impacts on prefrontal attentional network function in young adult brains. Psychopharmacology (Berl) 2007, 191:159-169.

10. Xu J, Mendrek A, Cohen MS, Monterosso J, Simon S, Brody AL, Jarvik M, Rodriguez P, Ernst M, London ED: Effects of acute smoking on brain activity vary with abstinence in smokers performing the N-Back task: a preliminary study. Psychiatry Res 2006, 148: 103-109.

II. Domino EF, Minoshima S, Guthrie SK, Ohl L, Ni L, Koeppe RA, Cross D], Zubieta J: Effects of nicotine on regional cerebral glucose metabolism in awake resting tobacco smokers. Neuroscience 2000, 101:277-282.

12. Rose JE, Behm FM, Westman EC, Mathew RJ, London ED, Hawk TC, Turkington TG, Coleman RE: PET studies of the influences of nicotine on neural systems in cigarette smokers. Am J Psychiatry 2003, 160:323-333.

13. Stein EA, Pankiewicz J, Harsch HH, Cho JK, Fuller SA, Hoffmann RG, Hawkins M, Rao SM, Bandettini PA, Bloom AS: Nicotine-induced limbic cortical activation in the human brain: a functional MRI study. Am J Psychiatry 1998, I 55:1009-1015.

14. Kumari V, Gray JA, ffytche DH, Mitterschiffthaler MT, Das M, Zachariah E, Vythelingum GN, Williams SC, Simmons A, Sharma T: Cognitive effects of nicotine in humans: an fMRI study. Neuroimage 2003, 19:1002-1013.

15. Rose JE, Behm FM, Salley AN, Bates JE, Coleman RE, Hawk TC, Turkington TG: Regional brain activity correlates of nicotine dependence. Neuropsychopharmacology 2007, 32:244I-2452.

16. Hahn B, Ross TJ, Stein EA: Cingulate activation increases dynamically with response speed under stimulus unpredictability. Cereb Cortex 2007, 17:1664-167I.

17. Domino EF, Minoshima S, Guthrie S, OhI L, Ni L, Koeppe RA, Zubieta JK: Nicotine effects on regional cerebral blood flow in awake, resting tobacco smokers. Synapse 2000, 38:3I3-32I.

18. London ED, Connolly RJ, Szikszay M, Wamsley JK, Dam M: Effects of nicotine on local cerebral glucose utilization in the rat. Neurosci 1988, 8:3920-3928.

19. Zubieta J, Lombardi U, Minoshima S, Guthrie S, Ni L, Ohl LE, Koeppe RA, Domino EF: Regional cerebral blood flow effects of nicotine in overnight abstinent smokers. Biol Psychiatry 200I, 49:906-913.

20. Denson TF, Pedersen WC, Ronquillo J, Nandy AS: The angry brain: Neural correlates of anger, angry rumination, and aggressive personality. J Cogn Neurosci 2009, 21 :734-44.

21. Dougherty DD, Shin LM, Alpert NM, Pitman RK, Orr SP, Lasko M, Macklin ML, Fischman AJ, Rauch SL: Anger in healthy men: a PET study using script-driven imagery. Biol Psychiatry 1999, 46:466-472.

22. Kimbrell TA, George MS, Parekh PI, Ketter TA, Podell DM, Danielson AL, Repella JD, Benson BE, Willis MW, Herscovitch P, Post RM: Regional brain activity during transient self-induced anxiety and anger in healthy adults. Biol Psychiatry 1999, 46:454-465.

23. Rosvold HE, Schwarcbart MK: Neural structures involved in delayed-response performance. In The frontal granular cortex and behavior Edited by: Warren JM, Akert K. New York: McGraw-Hill; 1964:I-15.

24. Divac I: The prefrontal system: a smorgasbord. Progress in Brain Research 1994, 100:169-175. 
25. Fallon $\mathrm{JH}$, Keator D, Mbogori J, Potkin SG: Hostility differentiates the brain metabolic effects of nicotine. Brain Res Cogn Brain Res 2004, I 8: |42-148.

26. Bushman BJ: Moderating role of trait aggressiveness in the effects of violent media on aggression. J Pers Soc Psychol 1995, 69:950-960.

27. Talairach J, Tournoux P: Co-planar stereotaxic atlas of the human brain Stuttgart: Thieme; 1988.

28. Friston K, Ashburner J, Kiebel S, Nichols T, Penny W, (Eds): Statistical parametric mapping: The analysis of functional brain images. London: Academic Press; 2007.

29. Kilpatrick L, Cahill L: Amygdala modulation of parahippocampal and frontal regions during emotionally influenced memory storage. Neuroimage 2003, 20:2091-2099.

30. Cahill L, Haier RJ, White NS, Fallon J, Kilpatrick L, Lawrence C, Potkin SG, Alkire MT: Sex-related difference in amygdala activity during emotionally influenced memory storage. Neurobiol Learn Mem 200I, 75: I-9.

31. Fallon JH, Keator DB, Mbogori J, Taylor D, Potkin SG: Gender: a major determinant of brain response to nicotine. Int J Neuropsychopharmacol 2005, 8: 17-26.

32. Breiter HC, Etcoff NL, Whalen PJ, Kennedy WA, Rauch SL, Buckner RL, Strauss MM, Hyman SE, Rosen BR: Response and habituation of the human amygdala during visual processing of facial expression. Neuron 1996, 17:875-887.

33. Critchley HD, Wiens S, Rotshtein P, Ohman A, Dolan RJ: Neural systems supporting interoceptive awareness. Nat Neurosci 2004, 7:189-195.

34. lidaka T, Omori M, Murata T, Kosaka H, Yonekura Y, Okada T, Sadato $N$ : Neural interaction of the amygdala with the prefrontal and temporal cortices in the processing of facial expressions as revealed by fMRI. J Cogn Neurosci 200I, 13:1035-1047.

35. Irwin W, Davidson RJ, Lowe MJ, Mock BJ, Sorenson JA, Turski PA: Human amygdala activation detected with echo-planar functional magnetic resonance imaging. Neuroreport 1996, 7:1765-1769.

36. Lane RD, Reiman EM, Bradley MM, Lang PJ, Ahern GL, Davidson RJ, Schwartz GE: Neuroanatomical correlates of pleasant and unpleasant emotion. Neuropsychologia 1997, 35:|437-|444.

37. Lee GP, Meador KJ, Loring DW, Allison JD, Brown WS, Paul LK, Pillai J, Lavin TB: Neural substrates of emotion as revealed by functional magnetic resonance imaging. Cogn Behav Neurol 2004, 17:9-17.

38. Morris JS, Frith CD, Perrett DI, Rowland D, Young AW, Calder AJ, Dolan RJ: A differential neural response in the human amygdala to fearful and happy facial expressions. Nature 1996, 383:8I2-8I5.

39. Morris JS, Friston KJ, Buchel C, Frith CD, Young AW, Calder AJ, Dolan RJ: A neuromodulatory role for the human amygdala in processing emotional facial expressions. Brain 1998, I 2 I (Pt I):47-57

40. Phillips ML, Young AW, Senior C, Brammer M, Andrew C, Calder AJ, Bullmore ET, Perrett DI, Rowland D, Williams SC, Gray JA, David AS: A specific neural substrate for perceiving facial expressions of disgust. Nature 1997, 389:495-498.

4I. Schneider F, Grodd W, Weiss U, Klose U, Mayer KR, Nagele T, Gur RC: Functional MRI reveals left amygdala activation during emotion. Psychiatry Res 1997, 76:75-82.

42. Davidson RJ, Putnam KM, Larson CL: Dysfunction in the neural circuitry of emotion regulation - a possible prelude to violence. Science 2000, 289:59|-594.

43. Phan KL, Fitzgerald DA, Nathan PJ, Moore GJ, Uhde TW, Tancer ME: Neural substrates for voluntary suppression of negative affect: a functional magnetic resonance imaging study. Biol Psychiatry 2005, 57:210-219

44. Raine A, Buchsbaum M, LaCasse L: Brain abnormalities in mur derers indicated by positron emission tomography. Biol Psychiatry 1997, 42:495-508.

45. Warburton DM: Psychopharmacological aspects of nicotine. In Nicotine Psychopharmacology: Molecular, Cellular and Behavioral Aspects Edited by: Wonnacott S, Russell MAH, Stolerman IP. New York: Oxford University Press; 1990:77-III.

46. Marci CD, Glick DM, Loh R, Dougherty DD: Autonomic and prefrontal cortex responses to autobiographical recall of emotions. Cogn Affect Behav Neurosci 2007, 7:243-250.
Publish with Biomed Central and every scientist can read your work free of charge

"BioMed Central will be the most significant development for disseminating the results of biomedical research in our lifetime. "

Sir Paul Nurse, Cancer Research UK

Your research papers will be:

- available free of charge to the entire biomedical community

- peer reviewed and published immediately upon acceptance

- cited in PubMed and archived on PubMed Central

- yours - you keep the copyright 